\title{
REDUCED ADVERBIAL CLAUSE IN ENGLISH
}

\author{
Dwi Lia Rakhmasari \\ Universitas Putra Bangsa Kebumen, Indonesia \\ Email of corresponding author: dwiliarakhmasari@gmail.com
}

\begin{abstract}
Human cannot communicate with one another without language. Good language will affect the effectiveness of the information delivery. Using a good adverb clause is one of effective sentence example. However, the continuous use of adverb clauses will also create redundancies in the delivery of information. Therefore, it is necessary to have a variety of uses of adverb clauses, one of which is the use of reducing adverb clauses. This research provides a description of what elements that can be reduced in the Reduced Adverbial Clause and what changes that occurs in Reduced Adverbial Clause after the reduction process is carried out. The data of this research is collected from corpus with note-taking technique. This study uses qualitative methods with interactive techniques. Interactive technique covers three components, namely data reduction, data presentation and conclusion drawing. This research found that adverbial clause can be reduces as long as it has the same subject. Elements that can be reduced in adverbial clause are subject, subject and auxiliary, and conjunction. The changes of reduced clause can be in the form of present participle, past participle, and clause without subject and auxiliaries.
\end{abstract}

Keywords: Reduced Adverbial Clause, Language, Adverbial Clause

\section{INTRODUCTION}

Language is an important tool in society because of without language, humans cannot communicate with one another. In the current era of globalization, people, especially Indonesians, consider English to be an important language to learn. For Indonesian, English is the key of international currency in technology and trade. In order to follow this globalization era, people should master English in all aspects, including writing. Writing is an important activity in our life because we can convey messages to anyone without having to meet face to face. That forces the written language that we make should be made clear so as not to cause double interpretation. For example, what happens in magazines or newspapers which aim to convey information to readers so that they should use good language.

The use of good language will affect the effectiveness of the delivery of information. If a writer uses a complex and long-winded language structure, the delivery of information becomes ineffective. The effectiveness is closely related to the clause. The formation of a good clause will form an effective sentence as well. One type of clause that is often used is an adverb clause. However, the continuous use of adverb clauses will also create redundancies in the delivery of information. Therefore, it is necessary to have a variety of uses of adverb clauses, one of which is the use of omitting adverb clauses. 
Elimination of adverbial clauses not only occur in Indonesian but can also occur in English which is commonly referred to as reduced adverbial clause.

According to Azar (2002) reduced is a shortening of sentences with the same meaning and can occur in adverbial clauses and adjective clauses. According to Leech (1989:26) adverbial clause is a subordinate clause (subordinate clause) which acts as a statement of the main clause (main clause). Meanwhile, according to Parrot (2000: 334) adverbial clause is a category of subordinate clause that connects with the main clause and provides information about the main clause.

Indonesian people who are learning English usually have a lot of difficulties in doing adverbial clauses. Because there are some differences, for example, different forms of verbs in English with the addition of -ing or -ed while in Indonesian it is not. Reduction in adverbial clauses is often found in the TOEFL (Test of English as a Foreign Language). This is quite difficult for students or TOEFL test participants in determining the truth of a sentence. When someone reduces an adverbial clause, the writer must understand the rules for doing the reduction so that there is no dangling sentence. Sometimes many non-English native speakers do reductions in adverbial clauses that do not have the same subject as the main clause, resulting in a dangling sentence. As happened in the sentence playing in the street, the truck hits the child. The sentence when read at a glance looks like a logical sentence but after analyzing it more deeply there is a subject discrepancy.

According to Pyle and Page (2005:213) Dangling sentence is a discrepancy between what is explained and what is explained as happens in clause reduction when it is done in sentences that do not have the same subject. The example above causes multiple interpretations from listeners or readers, namely who is playing the truck or the child. This also seems to have arisen due to Indonesian language interference. In Indonesian, there are also examples of sentences that some speakers believe are logical, such as Ketika pulang sekolah, anjing itu menggigit saya.. In fact, if the sentence is analyzed more deeply, there is a subject discrepancy that results in ambiguous interpretation, namely who returned anjing or saya.

Reduced clauses in adverbial clauses are also commonly found in newspapers because the function of reduced clauses is to make sentences effective and efficient. Regarding the problems that occur to English language learners and the use of reduced clauses in adverbial clauses in everyday life, the researcher would like to provide a description of how an adverbial clause can be reduced. In this case, the author will provide a description of what elements that can be reduced in the Reduced Adverbial Clause and what changes that occurs in Reduced Adverbial Clause after the reduction process is carried out. This can be useful for English learner in writing a sentence without any dangling when they are reducing adverbial clauses. 


\section{METHOD}

The sources of data used in this research include documents. The documents used as the source of data are books and most used sentences in corpus. The data were obtained by note-taking techniques. Moleong (2014: 280) provides an explanation of data analysis techniques, which is a process of formally detailing efforts to find themes and formulate hypotheses (ideas) as suggested by the data, and an effort to provide support to these themes and hypotheses. This study uses qualitative methods with interactive techniques. Interactive technique covers three components, namely data reduction, data presentation and conclusion drawing (Miles Matthew \& Huberman, 2009: 16-20). Data reduction covers the centralization, simplification (summarizing, coding, and tracing according to the theme) of the raw data found during the data collection process in the field. The data is analyzed according to categories and variables. Then, researchers make an effort to draw conclusions and verification based on data reduction and data presentation. The data in this research limited only for compound sentences.

Compound sentences, both multilevel compound sentences and equivalent compound sentences, have two or more clauses that are related to each other. There are two ways to connect clauses in a compound sentence, namely by coordination and subordination. According to Alwi, et al. (2010: 396) coordination relationship is combining two clauses, each of which has an equal position in the sentence structure. The result is an equal unit. The relationship between the clauses does not involve the units that make up the hierarchy because one clause is not a constituent of another clause. While the subordination relationship combines two or more clauses to form a compound sentence in which one clause is part of the other clause. So the clauses in compound sentences arranged in a way of subordination do not have an equal position. In other words, in a compound sentence that is structured in a subordinating way, there is a clause that functions as a constituent of another clause. The relationship between the clauses is hierarchical. Therefore, compound sentences arranged in a subordinating manner are called multilevel compound sentences. According to Alwi, et al. (2010: 400) a subordinate clause can also be an adverb clause in the sense that the clause functions as an explanation.

According to Parrot (2000:334) in English there is also an adverbial clause, namely the category of subordinate clauses. Adverbial clauses are linked to the main clause and provide information about the main clause. Adverbial clauses can be preceded by conjunctions when, although, in order that and so on. These conjunctions are called subordinating conjunctions because unlike the words and, but or or, which divide two clauses of equal importance. According to Cruickshank and Ivanic (1989:26) an adverbial clause is a subordinate clause of a subordinate clause that acts as a provider of information from the main clause. Adverbial clauses answer questions such as when, why, and for what. 
Subordinating conjunctions usually consist of after, although, as, before, if, once, since, though, when, whereas, while, as if, as soon as, as long as, in that, in order that, so that, such that. So overall subordinating conjunctions consist of: time, place, means, reasons, resistance, circumstances, goals, and results. To facilitate understanding, it can be seen in the following table:

\begin{tabular}{|l|l|}
\hline \multicolumn{1}{|c|}{ Adverbial Clause } & \multicolumn{1}{c|}{ Conjunction } \\
\hline Time & $\begin{array}{l}\text { After, before, as, once, since, until, when, } \\
\text { whenever, while, as soon as }\end{array}$ \\
\hline Condition & $\begin{array}{l}\text { If, unless, as long as, provided (that), in } \\
\text { case }\end{array}$ \\
\hline Contrast & Although, whereas, while, even though \\
\hline Reason and Cause & Because, since, as \\
\hline Place & Where, wherever \\
\hline
\end{tabular}

Because this clause begins with a subordinating conjunction, it becomes a dependent clause. It is said that because this clause cannot stand alone, if it stands alone the message to be conveyed by the speaker is incomplete so it must be combined with an independent clause. For a deeper understanding, see the following illustration:

$\begin{array}{ll}\text { While I am cooking, } & + \\ \text { (Adverbial clause) } & \text { I like to listen to the radio. }\end{array}$

Merging two clauses either subordinating or coordinating can result in the presence of the same two elements in one sentence. The repetition of the same elements is a redundancy in terms of information. One of the syntactic tools to reduce the level of redundancy is the elimination or ellipsis which in English is known as reduced clause, namely the removal of certain elements from a sentence or text. For example, what happens in the sentence:

(After the voyagers were) launched 16 days apart, the voyagers were intended to fly by only Jupiter and Saturn

The sentence elements After the voyager written between brackets in the example above can be deleted without reducing the meaning of the sentence. The same element that is not removed is called the antecedent of the element that is removed. According to Alwi et al. (2010: 426), the deletion whose antecedent precedes the removed element is called anaphoric, while the depletion whose antecedent follows the removed element is called cataphoric. This is done because in formal writing, especially those of a scientific nature, it requires word savings so that omission is often used. 
An adverbial clause can only be omitted if the adverb clause has the same subject as the main clause. If the adverbial clause and the main clause do not have the same subject, a dangling sentence will occur. According to Pyle and Page (2005:213), the Dangling sentence is a discrepancy between what is explained and what is explained, as happens in the omission of the clause when it is done in a sentence that does not have the same subject.

\section{FINDING AND DISCUSSION}

\section{A. Elements that can be Reduced in the Reduced Adverbial Clause}

\section{Subject Reduction}

The subject can be reduced in the adverbial clause reduction provided that the subject in the adverbial clause is the same as the subject in the main clause. According to Parrot (2000: 337) an adverbial clause can be reduced by eliminating the same subject as the main clause. Because if you don't have the same subject, it will result in a dangling sentence. According to Pyle and Page (2005:213) Dangling sentence is a discrepancy between what is explained and what is explained, as happens in the omission of the elements of an adverb clause when it is done in a sentence that does not have the same subject. In English, the omission of the subject can occur in both active and passive sentences. As is the case in the following example:

(1) After a caterpillar spends some time in a cocoon, a caterpillar will emerge as a butterfly.

After spending some time in a cocoon, a caterpillar will emerge as a butterfly. (Active Sentence)

(2) After they left the road, they went into the deep resin-scented darkness of the trees

Leaving the road, they went into the deep resin-scented darkness of the trees. (Active Sentence)

(3)After Renfrewshire Enterprise try to sneak their plans through, Renfrewshire Enterprise are now trying to defuse the situation.

After trying to sneak their plans through, Renfrewshire Enterprise are now trying to defuse the situation. (Active Sentence)

(4) When 1996 to 2005 was compared to the ten year period prior to Order 888, 1996 to 2005 saw the number of new generations added each year .......

When compared to the ten year period prior to Order 888, 1996 to 2005 saw the number of new generations added each year increase ........ (Passive sentence)

(5) Yamada's top wrestlers shrug when Yamada's top wrestlers are asked about the hallowed nature of sumo.

Yamada's top wrestlers shrug when asked about the hallowed nature of sumo. (kalimat pasif) 
In examples 1, 2, 3, 4, and 5 above there are examples of obliteration or reduction of the subject. The same subject, namely a caterpillar, the, Renfrewshire Enterprise, 1996 to 2005, Yamada's top wrestlers which is also contained in the main clause can be omitted to reduce the repetition of the subject in the sentence.

\section{Subject and Auxiliary verb Reduction}

When an adverbial clause contains a subject followed by an auxiliary verb, the subject and auxiliary verb can be omitted. According to Leech (1989: 28) in the process of reducing the adverb clause, the result can be a clause without a subject and a verb. As is the case in the following example:

(6) When my mother was in the college, my mother met my father.

When in the college, my mother met my father.

(7) When I was only a child, I was taught soccer by my father.

When only a child, I was taught soccer by my father.

In examples 6 and 7 above, it can be seen that the subject and auxiliary verbs such as my mother was, I was can be omitted because they are already contained in the main clause. So that the adverb clause does not need to be repeated. However, even though the meaning is omitted, it remains the same. For example, the sentence When my mother was in the college, my mother met my father changed to When in the college, my mother met my father both of these sentences indicate that the subject in this case Mother is in college. So, to be able to make sentences more efficient, omission is very necessary.

\section{Conjunction Reduction}

Based on the data found by the author, the conjunctions that can be omitted in the reduced adverbial clause are the conjunctions in the adverbial clause that indicate time, indicate conditions, and indicate reasons and causes. This is corroborated by Lestari and Nurjaman (2012) that reduced clauses without conjunctions or subordinators have a semantic role in the form of clause of time (adverb clause indicating time), conditional clause (conditional adverb clause), and reason clause (adverb clause indicating cause). Examples of these can be seen below:

(8) They might be living with their parents, (while) (they) (saved) their salaries for designer handbags.

They might be living with their parents, saving their salaries for designer handbags.(time clause)

(9) (When) (you) (read) his quotes now, you're struck by two things

Reading his quotes now, you're struck by two things. (time clause) 
(10) (After) (they) (left) the road, they went into the deep resin-scented darkness of the trees

Leaving the road, they went into the deep resin-scented darkness of the trees. (time clause)

(11) (Because) (I) (was) unprepared for the test, I didn't do well.

Unprepared for the test, I didn't do well. (reason clause)

(12) (If) (suitable retrofit locations) (are) given the energy intensity of major point source heat emitters and the propensity for heavy industry to be located among other industrial consumers, suitable retrofit locations will have enough local demand .....

Given the energy intensity of major point source heat emitters and the propensity for heavy industry to be located among other industrial consumers, suitable retrofit locations will have enough local demand .....(conditional clause)

In examples 8, 9, 10, 11 and 12 above, it can be seen that in addition to the subject and auxiliary verbs, conjunctions such as while, when, because, if can be omitted. With the loss of the conjunction, the clause still acts semantically as a clause indicating time, reason and presupposition.

\section{B. Changes that Occur in Reduced Adverbial Clause}

In a compound sentence, if the adverbial clause and the main clause have the same subject, it can be reduced by changing the adverbial clause into another form that functions as an adverbial in the sentence. According to Parrot (2000: 337) the main requirement of the reduced adverbial clause is that both the adverbial clause and the main clause have the same subject. Reduction of the adverb clause can be done by removing the subject from the adverb clause and replacing the predicate (base verb) which is added with the suffix -ing for the active clause or -ed in the passive clause and it can also be done by removing the auxiliary verb. According to Parrot (2000:337) the results of adverbial clause reduction can be in the form of present participle, past participle, and subject and verbless. In order to better understand the form of these changes, see the following explanation:

1. Changes in the form of Present Participle

Reduction that produces the present participle is a reduction that is carried out on an adverbial clause in the form of an active clause. This reduction can be done by removing the subject and replacing the verb in the -ing form. As is the case in the following example: 
a. Time adverbial clause reduction since, after, before, as, once, since, until, when, whenever, while.

(13) Before the students sang the school song, the students recited a poem. Before singing the school song, the students recited a poem.

(14) After the police stopped the fight, they arrested two men and women.

After stopping the fight, the police arrested two men and women.

(15) Since Bob opened his new business, he has been working 16 hours a day.

Since opening his new business, he has been working 16 hours a day.

b. Cause and Reason Adverbial Clause Reduction

(16) Because Mary needed some cash, she wanted to find an ATM machine.

Needing some cash, Mary wanted to find an ATM machine.

c. Contrast Adverbial Clause Reduction

(17) Although Lina exercises everyday, she does not lose her weight.

Although exercising everyday, she does not lose her weight.

d. Condition Adverbial Clause Reduction

(18) If I planted the plant in front of my house, I will feel very fresh.

If planting the plant in front of my house, I will feel very fresh.

In the examples $13,14,15,16,17$, and 18 above, it can be seen that the active sentence (both past and present) after the subject is removed, the verb that follows is changed to the -ing form. For example, in example (16) because Mary needed some cash, she wanted to find an ATM machine. Deletion occurs in the subject and the verb needed is changed into -ing form, namely needing some cash, Mary wanted to find an ATM machine. Likewise in the active sentence Although Lina exercises every day, she does not lose her weight. After the subject (Lina) is removed, the verb exercises are changed into -ing form, which is the sentence although exercising every day, she does not lose her weight.

2. Changes in the Form of Past Participle

Reduction that produces a past participle is a reduction that is carried out on an adverbial clause in the form of a passive clause. Reduction can be done by removing the subject and auxiliary verb and leaving only the main predicate which is usually in -ed form (verb 3). As is the case in the following example:

a. Adverb of time since, after, before, as, once, since, until, when whenever, while (19) Once a language are learned, a language cannot easily be forgotten.

Once learned, a language cannot easily be forgotten. 
b. Reason and Cause Adverbial Clause Reduction (cause and effect adverb clause reduction)

(20) Because he was taught by Einstein, he became one of the best scientists of his age.

Taught by Einstein, he became one of the best scientists of his age.

c. Contrast Adverbial Clause Reduction

(21) Although It had been badly damaged in places, the chest fetched £3,500 at auction.

Although badly damaged in places, the shest fetched $£ 3,500$ ar auction.

d. Condition Adverbial Clause Reduction

(22) If it is firmly planted in a rich soil, the tree will grow very quickly.

If (firmly) planted in rich soil, the tree will grow very quickly.

In examples 19, 20,21, and 22, it can be seen that there is a change in the -ed form of the verb that occurs after the subject and auxiliary verb are removed. For example, it is found in the example sentence Once a language is learned, a language cannot easily be forgotten. After the subject, namely a language and the auxiliary verb, namely are omitted, the clause changes to a past participle which is in the form of -ed, namely Once learned, a language cannot easily be forgotten.

3. Changes in the form of clauses without subject and auxiliary verb

Reduction that produces a clause without a subject and an auxiliary verb is a reduction that occurs in an adverbial clause in an active time-testing sentence whose clause contains an auxiliary verb. This reduction can be done by eliminating the subject and auxiliary verb contained in the adverbial clause. For example, what happens in the following example:

(23) Old clocks are very valuable when they are in a good condition.

Old clocks are very valuable when in a good condition

(24) Once finally the ship was under way, the ship quickly made up for lost time.

Once finally under way, the ship quickly made up for lost time.

(25) When I am only a child, I am taught by my father how to play soccer.

When only a child, I am taught by my father how to play soccer.

In the examples of sentences 23, 24, 25 above, the adverbial clause which previously had a subject and also an auxiliary verb as in the examples they are, the ship was, I am can be removed or reduced but in essence, whether it is removed or not, the sentence is still have the same meaning. This needs to be done because if the subject and auxiliary verb are still used, it will create redundancies in the sentence. For example, it occurs in the sentence Old clocks are very valuable when they are in a good condition. After the 
subject they and the predicate are reduced into a form that does not contain a subject and an auxiliary verb, Old clocks are very valuable when in a good condition

\section{CONCLUSION}

It can be concluded that adverbial clause reduction can only be done when the adverbial clause and the main clause have the same subject. If you do not have the same subject, there will be dangling. This reduction can be done by removing the subject and changing the predicate into -ing or -ed form and without a verb. The result of the reduction of the first adverbial clause is the present participle which is marked with ing. This change occurs when the adverbial clause that is reduced is an active clause. The result of the second reduction is the past participle which is marked with -ed. This change occurs when the reduced adverbial clause is a passive clause. The result of the third reduction is without subject and verb less or without verb. This change occurs when the adverbial clause in the active sentence contains an auxiliary verb or (to be). Due to the limitations of this paper, it is necessary to conduct further research on reduced adverbial clauses so that the presentation will be clearer and better understood by the reader.

\section{REFERENCES}

Alwi, Hasan dkk. 2010. Tata Bahasa baku Bahasa Indonesia. Jakarta: Balai Pustaka

Azar, Bety Schramfer. 2002. Understanding and Using English Grammar. New York: Pearson Education

Leech, Geoffrey. 1989. An A-Z of English Grammar and Usage. Hongkong: Thomas Nelson and Sons.

Lestari, Maria Yosephin Widarti and Lukman Nurjaman. 2012. Analisis Reduced Adverbial Clauses. Bandung: Universitas Widyatama.

Miles Matthew, B., \& Huberman, A. M. 2009. Analisis Data Kualitatif: Buku Sumber Tentang Metode-metode Baru. Jakarta: Ul Press.

Moleong, L. J. 2014. Metodologi Penelitian Kualitatif edisi Revisi. Bandung: PT. Remaja Rosda Karya

Parrot, Martin. 2000. Grammar For English Language Teacher. United Kingdon: Cambridge University Press.

Pyle, Michael A. dan Mary Ellen Munoz Page. 2005. Cliff TOEFL Preparation Guide. New Delhi: Wiley Dreamtech India Ltd. 